\title{
DOKTEREN OVER DE WEST
}

$$
\text { DOOR }
$$

W. R. MENKMAN

Er wordt zoo bij buien heel wat gedokterd over de kwalen van onze West; meer bepaaldelijk bij het eeuwig zieke kind Suriname is den laatsten tijd weder de dokter om zoo te zeggen niet van de vloer.

En niet eens behoeft men ten deze te spreken in overdrachtelijken zin alleen, want kort achter elkander spraken twee wezenlijke medici zich in het openbaar uit over Westindische en vooral Surinaamsche nooden.

Bedoeld worden de Dirig. Offic. v. Gezondh. P.Cool in het Koloniaal Weekblad van 17 Febr. „Twee deelen van Tropisch Nederland (Suriname en de Molukken)" en Dr. Th. J. Lens in het Handelsblad van 24 en 25 Febr. „Naar Suriname. Een pleidooi voor emigratie van Neder„landers."

De Heer Cool vestigt er de aandacht op dat het steeds wederkeerende Surinaamsche nadeelige begrootings-saldo slechts daardoor een doorn is in veler oog, omdat die lastpost zich ieder jaar opnieuw als „Bijdrage uit 's Rijks schatkist tot aanvulling der Surinaamsche geldmiddelen" bij de moederlandsche Volksvertegenwoordiging komt aandienen, terwijl sommige Oostindische gebieden, en met name de Molukken, even goed armlastig zijn, maar niemand zich daar het hoofd over breekt, omdat het feit bij de groote massa niet bekend is; de Oostindische begrooting immers geeft geen specificatie van de „rentabiliteit" van ieder gewest afzonderlijk.

Dr. Lens doet heel wat anders, en heel wat meer, dan vergelijkingen maken, hij geeft een middel aan de hand tot Suriname's ook economische gezondmaking, en dat 
middel zou zijn emigratie van Hollandsche boerenjongens naar ginds.

De belangstelling welke beide medische heeren aan den dag leggen, waarvan de eerste slechts enkele jaren geleden, de laatste eenige tientallen van jaren terug, in Suriname leefde en werkte, bewijst wederom hoezeer de aangelegenheden van dit gewest hun ter harte blijven gaan die daar een grooter of kleiner deel van hun leven hebben gesleten.

Anders dan met groot genoegen zullen wel geen vrienden van Suriname het opstel van den heer Cool hebben gelezen en het verdient zeker in nog ruimer kring bekend te zijn dan bij de lezersschare van het $\mathrm{K}$. W.

Niet alleen omdat zijn vergelijking tusschen twee zoo ver van elkander verwijderde en oogenschijnlijk zoo verschillende deelen van Tropisch Nederland zulke interessante gezichtspunten opent, maar vooral omdat hij, wel verre van Suriname zijn armlastigheid te verwijten, wat al zoo vaak en in zoovele verschillende toonaarden is geschied, het de vertroosting brengt van in dat opzicht niet alleen te staan, niet in de West (Curaçao geniet ook nog steeds ,subsidie”), maar zelfs niet in Tropisch Nederland als geheel. Dit geeft zeker verademing; sedert mijn publicatie van Maart 1919 („Nederland en West-Indië één", uitg. W. I. Kamer) is het geluid dat ergernis over de subsidie niet het oordeel over Surinaamsche aangelegenheden geheel mag beheerschen maar al te weinig vernomen.

Dr. Lens heeft zich zooals gezegd een heel wat omvangrijker taak gekozen dan vergelijkingen te geven; hij prijst een geneesmiddel aan tegen de Surinaamsche kwaal en neemt daarmede, uit den aard der zaak, het risico op zich van veel critiek en veel bestrijding.

Vooral ook omdat het middel niet nieuw is en nog nooit is aanbevolen geworden zonder dat ook onmiddellijk ernstige bedenkingen ertegen zich als van zelf opdrongen.

En zoo noodigt ook thans weder Dr. Lens' pleidooi voor emigratie van blanken uit N. W. Europa naar Suriname tot bestrijding en tegenspraak uit. 
Gaarne zal men op zijn gezag willen aannemen dat, theoretisch, zware lichamelijke arbeid van blanken in de tropen, mits onder gunstige hygiënische omstandigheden, zeer goed mogelijk is, maar dat practisch deze waarheid zou zijn bewezen door een proefneming op groote schaal, t. w. bij de doorgraving der landengte van Panama, kan zoo maar niet worden aanvaard. Dat in 1911 Colonel Goethals 44.000 menschen aan het werk had, waaronder 12.000 blanken, en het sterftecijfer niet hooger was dan dat onder de grondwerkers bij het aanleggen eener subway in New York moge waar zijn, maar men zou dan toch wel eens willen weten hoeveel van die 12.000 blanken dezelfde soort werk deden als de 32.000 Jamaicanegers en andere gekleurden, hoeveel verloop er was onder het blanke arbeiders-element en hoeveel witmenschen men in de Canal Zone op den duur voor handen-arbeid heeft aangehouden.

Die zone te bevolken, en dan nog wel met blanken, is nimmer de bedoeling geweest van de Ver. Staten en dat de aan zwaren handenarbeid gewende blanke man zich geen ontijdigen dood op den hals behoeft te halen wanneer hij eens gedurende eenigen tijd, aangelokt door abnormaal hooge loonen, een tropische streek tot terrein zijner werkzaamheid maakt, daarvoor behoeft het succes der Amerikanen op de Landengte niet als voorbeeld te worden aangehaald. Ieder die de laatste jaren op Curaçao is geweest heeft kunnen opmerken hoe bij het oprichten van een nieuw tankpark en andere constructiewerkzaamheden voor de petroleum-onderneming Hollandsche arbeiders de felle tropische zonnehitte bij groote lichamelijke inspanning goed verdroegen, zelfs met verwaarloozing, in sommige opzichten, der strengere eischen van de hygiëne.

Een krachtproef als die der Hollandsche klinkers, fitters etc. op het droge, rotsachtige en niet beboschte $\mathrm{Cu}-$ raçao heeft natuurlijk weinig waarde als voorbeeld voor de eventueele bevolking door Hollandsche emigranten van het vochtige, grootendeels met tropisch oerwoud bedekte Suriname, maar het succes van Goethals en Gorgas 
op de Landengte van Panamá heeft met het vraagstuk in kwestie evenmin veel te maken. In geen van beide gevallen immers ging het om kolonisatie, om blijvende vestiging van blanken in de tropen, die aldaar van den landbouw zouden moeten bestaan en zich zouden moeten vermenigvuldigen, om aan een krachtig ras van keerkringEuropeanen het aanzijn te geven.

Neen, het desastreuze resultaat der kolonisatie-proef van 1845 moge uitsluitend te wijten zijn geweest aan de verwaarloozing der hygiëne, en Kapplers Wurtenbergers mogen flinke houthakkers zijn geweest, een proefneming op groote schaal met Europeesche landarbeiders in de tropen onder gunstige sanitaire omstandigheden is nimmer geslaagd, om de eenvoudige reden dat zulk een experiment nimmer heeft plaats gehad. Ook is Cuba geen goed voorbeeld van een tropenland met blanke arbeiders en de Zuidelijke Staten van Amerika mogen evenmin als zoodanig worden aangemerkt, hoewel Dr. Lens ons dat wil doen gelooven.

De Europeanen die op Cuba gingen werken (Zuid-Europeanen wel te verstaan) waren altijd seizoen-arbeiders en in de Zuidelijke Staten van Amerika ziet men met de grootste bezorgdheid den uittocht aan van de negers, die, aangetrokken door hooge loonen, naar het Noorden emigreeren.

Hoogstens kan men Dr. Lens toegeven dat het tropische oerwoud zich door middel van ziektekiemen tegen het doordringen van den mensch, onverschillig of hij blank is of gekleurd, verdedigt, en met hem verband zoeken tusschen klimaat en bodemgesteldheid eenerzijds en bevolkingsdichtheid anderzijds, ook in de tropen. Wanneer men daarbij dan maar heel voorzichtig is en niet vergeet dat er ook nog zoovele andere factoren hebben gewerkt.

Het is inderdaad merkwaardig dat in tropisch ZuidAmerika het vasteland overal zeer schraal bevolkt is en groote bevolkingsdichtheid alleen op enkele eilanden voorkomt (Barbados, Porto Rico, Haïti).

De juistheid der door Dr. Lens gegeven tegenstellingen

West Indische Gids IX 
Mexico-Amazonegebied en Abessinië-Congogebied buiten onderzoek latende moet toch bezwaar worden gemaakt tegen zijn andere antithese, blijkbaar in hetzelfde verband, Curaçao-Suriname, al ware het maar alleen op grond van de bedenking dat een plantage-land heel iets anders is dan een slaven-depôt. Maar, afgezien daarvan lijkt het toch heel weinig juist om te zeggen dat waar Suriname een schaarsche en slappe bevolking heeft, Curaçao overbevolkt geraakt is, van blanken zoowel als van negers.

Ook zou men Dr. Lens kunnen vragen wat hij eigenlijk bedoelt wanneer hij zegt uit eigen Curaçaosche ervaring te weten tot welken physieken arbeid Europeanen of hunne afstammelingen in de tropen in staat zijn; er was in zijn tijd op Curaçao nog geen petroleum-industrie.

Doch, om niet langer te spreken over bijzaken, welke belangrijke vragen zouden niet op absoluut bevredigende wijze moeten worden beantwoord (is dit mogelijk?) alvorens in ernst zelfs maar zou kunnen worden gedacht aan kolonisatie van Hollandsche plattelanders in Suriname, op groote schaal wel te yerstaan, om zoodoende Suriname te bevolken, „binnen een menschenleeftijd” nog wel.

In de eerste plaats kan moeilijk op gezag van Dr. Lens worden aangenomen dat zulk een grootsche onderneming niet alleen in het belang zou zijn van Suriname, maar ook van Nederland, en van de Nederlandsche landbouw-bevolking.

Van een specifiek Surinaamsch belang kan moeilijk meer sprake zijn wanneer men zich voorstelt zijne zorgen speciaal te wijden aan de blanke nieuwkomers en van stonde afaan, zooals Dr. Lens wil, een scheidsmuur op te richten tusschen de laatsten en de tegenwoordige bevolking, die men wel niet, zooals de menschlievende zegsman van Dr. Lens, door een groote inundatie uit hun lijden wil helpen, maar toch blijkbaar niet geschikt acht om, onder betere voorwaarden levende dan thans, zich te vermenigvuldigen en tot welvaart te geraken.

En zou het belang van het moederland inderdaad zijn 
gebaat bij een uittocht en masse van hare kinderen, om het ruim drie maal zoo groote Suriname te gaan bevolken? Voorloopig lijkt het verstandiger ruimte en werkgelegenheid te vergrooten door de Zuiderzee droog te maken en heide en andere woeste gronden te ontginnen, dan te trachten van Suriname een ,white men's country” te maken.

Toen de Zuidafrikaansche republieken haar onafkankelijkheid verloren verdween voor Nederland de laatste kans op voortplanting van het eigen ras in een vreemd werelddeel, daarbij zullen we ons moeten neerleggen.

Maar, en dat is wel de allerbelangrijkste vraag, wat zal de Hollandsche landarbeider zelf er van zeggen wanneer men hem uitnoodigt om, met zijn gezin (want met de inheemschen mag hij immers geen contact hebben) naar Suriname te emigreeren, zoodra de Regeering hem verzekert dat dit land, thans volgens Dr. Lens nog een der ongezondste van de wereld, geen gevaar meer oplevert voor zijn leven en gezondheid? Moeten daartoe eerst de geheele 15 miljoen $\mathrm{H}$. A. oerbosch worden op geruimd en zal er dan iets overblijven dat voor de blanke kolonisten waarde heeft?

Hoe moeten die kolonisten tot welvaart komen? Een klein aantal blanke landbouwers kan in een tropenland onder gunstige omstandigheden altijd wel vooruitkomen, met tuinbouw, veeteelt en sommige boomenculturen, maar de massa?

Dr. Lens wil hen laten werken in de suiker-, rijst- en katoenvelden (als daglooners?) en hun intellect en plichtsgevoel, hunne betere gezondheidstoestand, en de hulp van landbouw-machines, moeten hun arbeid zóó productief maken dat zij aandeelhouders en eigenaars kunnen worden van de bedrijven waarin zij hun kolonistenbestaan zullen aanvangen.

Wie kan ons voorrekenen dat de meerdere arbeidsprestatie van den blanke, plus de hulp der machine, zulk een gunstige ommekeer kan teweegbrengen in het tropische landbouw-bedrijf, dat thans in Suriname niet rendabel is, ondanks den vergelijkenderwijs zoo goedkoopen koelie-arbeid? 
Suriname, zegt het Jaarboekje van de Haagsche Post voor 1924, omvat het grondgebied bekend onder de benaming van Nieuw Guinea, een aardrijkskundige mystificatie mogelijk wel verband houdende met het bekende feit dat de Westindische slaven van de Kust van Guinee afkomstig waren.

Eigenlijk verdient een land waar zulk soort informatie door de drukpers verspreid wordt geen Suriname te bezitten, maar als putje bij paaltje komt willen wij het toch gaarne behouden; de Studie-commissie uit het Suriname Studie Syndicaat schreef dat wij er meer dan anderen recht op hebben en Dr. Lens vreest zelfs dat wij het, indien het in overwegende meerderheid met Aziaten bevolkt zou zijn, zouden kunnen verliezen. De Javanen, zegt hij, brengen hun hadjis, hun vrouwen(!), hun bijgeloof en hun Oostersche mentaliteit mede.

$\mathrm{Nu}$ is in de koloniale geschiedenis de los-van-het-moederland-beweging niet bepaald van Oosterschen oorsprong en men zou eerder geneigd zijn te concludeeren dat zij in het algemeen tot nu toe meer succes heeft gehad naar mate er op het punt van ras en cultuur meer affiniteit bestond tusschen de kolonie en het stamland, en niet te vergeten naar mate de kolonie economisch het moederland beter kon missen.

Intusschen, voor het oogenblik bestaat Suriname's bevolking reeds voor een zeer aanzienlijk deel uit menschen van Aziatisch ras en er bestaat geen goede reden om te vreezen dat deze op den duur minder loyaal zullen blijken dan de z.g. creolen en het politieke bewustzijn hun parten zal gaan spelen voordat de economische onafhankelijkheid een voldongen feit is.

De Oosterling houdt op een ,inlander” te zijn zoodra hij Surinaamsch grondgebied betreedt, zelfs al is het als contract-koelie, en de nakomelingschap van den Aziatischen kolonist leeft vanaf de geboorte onder geheel an. dere sociale, politieke en economische omstandigheden dan die welke de oorspronkelijke immigrant in het land zijner herkomst had gekend; deze voorname factor mag zeker niet over het hoofd worden gezien. 
De Oostersche mentaliteit te willen vergelijken met de Afrikaansche heeft misschien weinig practische waarde, maar daarom is het toch niet geheel zonder beteekenis dat de Amerikaansche neger, dien wij toch reeds eeuwen lang in den nieuwe wereld hebben kunnen observeeren, nimmer heeft getoond zich zijn stamverwantschap met zijn broeders in het zwarte werelddeel sterk bewust te zijn; in de V. S. heeft hij zelfs zijn Afrikaansche folklore geheel vergeten.

En wanneer het gaat om de geschiktheid der gepigmenteerde rassen, uit een oogpunt van volkskracht, om andere tropische gebieden te bevolken dan die waarin zij historisch schijnen thuis te behooren, die geschiktheid mag uit den aard der zaak bij hen veiliger à priori worden aangenomen dan bij N. W. Europeanen, met betrekking tot welke laatsten zij op zijn zachtst gesproken zeer dubieus is.

In 1848 moge de vrees hebben bestaan dat de negers na de emancipatie spoedig zouden uitsterven (zeker omdat zij de voorrechten der slavernij zouden moeten ontberen, want de aanvoer uit Afrika had toen allang opgehouden), maar die vrees is dan niet bewaarheid geworden; 63 jaar later spreekt Frederick A. Ober in zijn Guide to the WestIndies and Bermudas van ,that West Indian parasite, the ubiquitous negro". En de „teeming millions" van Vooren Oost-Indië pleiten allerminst tegen de vitaliteit van Hindoe en Javaan.

Zeker, de medicus heeft gelijk wanneer hij Suriname, zooals de toestand er thans is, van zijn standpunt ziet als één groot ziekenhuis, maar dan stelle men alle middelen in het werk om de volksgezondheid aldaar te verbeteren. Die taak schijnt, vergelijkenderwijs, niet bovenmatig zwaar, wanneer men H. F. Tillema's campagne voor het volkswelzijn in den Oost heeft gevolgd.

De publicaties van Dr. P. H. J. Lampe illustreeren in welke mate betere hygiëne niet alleen de arbeids-geschiktheid zou kunnen opvoeren, maar ook de numerieke sterkte der huidige bevolking zonder immigratie zou kunnen doen toenemen, en de Amerikanen gaan prat op de ver- 
meerdering der bevolking van Porto Rico sedert den aanvang hunner administratie over het eiland, 46 à $50 \%$ in 30 jaar, eveneens zonder immigratie, en niet minder op den verbeterden gezondheidstoestand, wat zeker voor een niet gering deel is te danken aan onvermoeide overheidszorgen.

Het Surinaamsche bevolkings- vraagstuk kan door immigratie alleen niet worden opgelost; de reeds aanwezige bewoners verdienen ook de aandacht en een natuurlijke aanwas wordt goedkooper verkregen dan eene door aanvoer van buiten.

Hetgeen niet zeggen wil dat wanneer het moederlandsche, het Oostindische of des noods het buitenlandsche kapitaal aandringt op het opheffen van belemmerende immigratie-bepalingen welke aan de vestiging van groote landbouw-bedrijven in Suriname in den weg zouden staan, niet binnen de uiterste grenzen der mogelijkheid moet worden getracht om dien wensch te bevredigen, vooral omdat uiteindelijk aanvoer van plantage-arbeiders beteekent permanente vestiging van landbouwers.

De koelie van heden is de kolonist van morgen, maar juist als kolonist zal hij in aanmerking komen voor overheidszorg in velerlei opzicht; de kolonist van de naaste en de verder verwijderde toekomst zal te dien aanzien niet in andere omstandigheden verkeeren dan die van heden, onverschillig of deze laatste van slaven - dan wel van koelie-afkomst is.

En het is ten slotte de kolonist die in de ruimere beteekenis het land moet vooruitbrengen. Men stare zich niet blind op den vroegeren, gouden, tijd van Suriname, toen daar naar beweerd wordt de grondslagen werden gelegd voor latere Heerengrachts-fortuinen; een slaven-kolonie, waar de groote meerderheid der bevolking evenmin stoffelijke bezittingen heeft als persoonlijke vrijheid geniet, is volgens onze tegenwoordigge opvattingen geen welvarend land. En een gewest in hoofdzaak bevolkt door koelies, eveneens niet-bezitters, zou dien naam evenmin verdienen.

De taak welke Nederland ten aanzien van Suriname te 
vervullen heeft houdt niet op bij het bevorderen van de immigratie; en het vraagstuk der kolonisatie in zijn geheel omvat zelfs nog meer dan een vergaande en voortgezette zorg voor de volksgezondheid.

Die taak is er een van volksopvoeding en volksontwikkeling, ook in economischen zin, in de meest algemeene beteekenis.

Vooral wanneer het menschen-materiaal, ook in de toekomst, uit gekleurden zal bestaan, en dat lijkt ondanks de pleidooien van Dr. Lens en van anderen voor emigratie van Nederlanders, toch wel het meest waarschijnlijke, dan zullen de kolonisten niet uit zich zelf tot welvaart komen, wanneer men hen maar in de meest gunstige hygiënische omstandigheden plaatst.

Daarvoor is veel meer noodig op het punt van overheidszorg; en landbouw-onderwijs in den engeren zin is ook al weder niet het eenige vereischte. Volkomen begrijpelijk is het dat de ook op onderwijs-gebied deskundige Surinaamsche medewerker van het Koloniaal Weekblad zich voortdurend kwaad maakt wanneer de opinie wordt verkondigd dat tegenwoordig in Suriname de negerkinderen (waar blijven de kinderen van de Aziatische ingezetenen?) naar Nederlandsch model met schoolsche wijsheid zouden worden volgepropt, in plaats van voor den landbouw opgeleid, een opvatting welke in haar algemeenheid zeker slechts misverstand kan kweeken of bestendigen.

Overheidszorg en wettelijke maatregelen kunnen weliswaar in het algemeen slechts beletselen wegnemen welke aan de economische ontwikkeling van een land in den weg staan, veeleer dan dat zij rechtstreeks welvaart kunnen scheppen, maar de Surinaamsche bevolking heeft uithoofde eener bizondere verhouding wel het recht in de eerste plaats op hulp en leiding van hooger hand te rekenen, waar het geldt het gebruik leeren maken en het ontwikkelen van de inderdaad aanwezige natuurlijke welvaartsbronnen des lands, dat maar in betrekkelijken zin haar eigen land kan worden genoemd.

Met uitzondering toch van de weinig talrijke Indianen 
is de geheele bevolking van Suriname van elders afkomstig; Afrikaan en Aziaat, de eene als slaaf onder dwang, de andere als koelie onder leiding en door contract gebonden, zijn gekomen, en de laatstgenoemde zal ook in de toekomst blijven komen, allereerst ten dienst van Europeesche belangen.

En zoo zou men er haast toe komen om aan het beruchte „lanti sa pai” een ondergrond van althans eenige rechtvaardigheid toe te kennen.

Epe, Maart 1927. 